Article

\title{
Proposal for Sustainable Dynamic Lighting in Sport Facilities to Decrease Violence among Spectators
}

\author{
Raquel Amorim ${ }^{1}$, Valentín Molina-Moreno ${ }^{2}$ and Antonio Peña-García ${ }^{1, *}$ \\ 1 Department of Civil Engineering, University of Granada, Granada 18071, Spain; \\ raquelamorim@correo.ugr.es \\ 2 Department of Management, University of Granada, Granada 18071, Spain; vmolina2@ugr.es \\ * Correspondence: pgarcia@ugr.es; Tel.: +34-958-249-435 \\ Academic Editor: Joo Hwa (Philip) Bay \\ Received: 16 October 2016; Accepted: 7 December 2016; Published: 10 December 2016
}

\begin{abstract}
Violence among spectators at sports events has become a serious problem, not only for its evident impact on safety, but also from the perspective of environmental, cultural, economic and social sustainability. Although it could be considered a purely social problem, some solutions could come from a smart and efficient design and management of the lighting installations. Thus, the management of sports installations requires deep considerations of lighting technology for three reasons: (1) accurate illumination allows the users to achieve their visual task with comfort and safety; (2) the energy consumption of sports facilities can be decreased with an efficient design of the lighting installation; and (3) the lighting impacts some psychological and physiological aspects such as arousal, stress or relaxation which are directly related to violence. In this work, the recent advances on the matter of light sources and non-visual effects of light are deployed within a new proposal of dynamic Light-emitting diode (LED) lighting to decrease violence among spectators. Here, sustainable sports facilities are considered from a global perspective where accurate illumination in each zone (court, bleachers, training rooms and surrounding streets) plays an important role in violence avoidance.
\end{abstract}

Keywords: lighting installation; sustainability; violence; sport facility; LED

\section{Introduction}

Violence and aggressive behavior are unfortunate events that have become increasingly common in sports. Given its huge impact from the perspectives of safety, economy and consumption of all kind of resources, several studies have proposed actions to minimize such acts [1]. Their impact is so deep that it has led authorities to take actions such as the "European Convention on Spectator Violence and Misbehaviour at Sports Events and in particular at Football Matches" (Council of Europe, 1985) after the tragic events at football matches involving fans. In order to prevent and end violence and invasions of the field by the spectators, the convention stipulates that each country undertakes adopting the necessary measures to implement the provisions laid down in the agreement. Besides being a challenging and complex task, a greater commitment is needed due to the relative importance of a number of factors that contribute to sports violence and to propose efficient and economical solutions to this problem. Beyond Europe, the cost of violence at sports events in financial and personal terms has been a big concern in countries such as the US, where breaking news shocked the public some years ago: due to serious injuries to one man after a match, a jury fined the corporation of one baseball team. The fine reached a 13.9 million dollar award to the victim [2]. In Australia, the National Committee on Violence indicated in 1990 that illegitimate violence in sports is an issue of concern in Australian society [3].

In addition to this perspective based on the personal and financial impact of violence in sports, there have been detailed studies from the psychological and sociological points of view. Terry [4] 
suggests that a process of socialization is the main determinant of violence in sports, reporting also that this process is more important than other factors which also play a mediating role. A conceptual model of the aggression process is presented as a way to reduce violent behavior, positing that socialization forces are the most easily manipulated to control violence in sports. In the study presented by Donahue [5], the relationship between harmonious passion and obsessive and aggressive behavior in sports showed that athletes with a predominant obsessive passion for basketball reported higher levels of aggression than athletes with a harmonious passion on the aggression scale. This study also shows that having an obsessive love is associated with aggressive behavior, especially under the threat of identity. Thus, the love you feel for sports can lead to maladaptive interpersonal behavior, especially if that love is rooted in a sense of identity that depends on doing well in this sport. In a study on the aggressive behavior of the players, Martin et al. [6] present different playing conditions and individual characteristics of the athletes. For the authors, an aggressive action was defined as a repetition of defection after a negative outcome resulting from that choice (i.e., a loss in both payoff and power).

In summary, we can say that violence is related to various emotional factors involving both the spectators and the sports athletes.

The considerations above show that violence at sports events has been studied in depth from two different perspectives: the study of violence among athletes and the study of violence among spectators. A proposal to decrease the latter based on a new illumination system will be the object of this research.

The reason for this proposal arises from an important lack in the field of applied illumination: although emotional factors have been proven to be directly related to light exposure $[7,8]$, no concrete actions on the illumination of sport facilities have been proposed to decrease violence among spectators to date.

On the other hand, it is known that some important physiological processes in the human body are related to the control of the biological clock and the regulation of some important hormones through circadian rhythms whose secretion and inhibition are mediated by light exposure [9].

Besides this impact from both physiological and psychological perspectives, the huge amount of energy consumed by the lighting installations of sport facilities as well as the strict visual needs of athletes and spectators demonstrate that a good, profitable and sustainable management of lighting is really necessary in sports facilities.

Anyhow, the design and implementation of accurate lighting installations begin with the choice of light sources to provide the necessary lighting levels in different areas of the facility. The recent advances in lighting source technology provide engineers, trainers and health professionals with an opportunity to consider this powerful tool to achieve their objective. However, the impacts of some of these advances are still unknown or not fully implemented in sports installations.

In the following subsections, the most relevant aspects of light sources and non-visual effects of light are summarized and presented as tools to decrease violence among spectators.

\subsection{Technology of Light Sources: New Opportunities for Effective and Sustainable Management of Sport Facilities}

The ergonomics of the physical environment should be aware of the effects of noise, vibrations, heat and cold, inappropriate light and other factors that can damage the environment, health, safety, and comfort and commitment of the people [10]. The lighting of sports facilities in terms of lighting levels, uniformity, color temperature and color reproduction is essential because lighting ergonomics methods must be continuously developed. From small to large multifunctional stadiums, good visibility in the field helps players to perform at their best whereas accurate light sources help spectators and modern High Definition (HD) cameras to capture the action. In parallel, good lighting conditions in the surroundings of the stadium enhance the safety of spectators before and after the competition.

Beyond these facts related to human factors, architectural lighting enhances the necessary atmosphere to attract visitors, making the events more profitable. In addition, last but not least, 
sports installations must also be sustainable from the perspective of energy consumption. These items are highly dependent on the choice of light sources.

There are different types of light sources used traditionally used in sports facilities. Here, the term "sports facility" is considered from a wide perspective, including sports fields, training rooms and gyms, grades, parking and the surroundings of stadiums, etc.

After years of the supremacy of incandescent lamps in both street and indoor lighting, the use of discharge lamps prevailed in public lighting for a long time and, after the controversial prohibition of non-halogen incandescent lamps, they were also outlined as one of the only options for indoor lighting. Indeed, the so-called "energy-saving lamps" provided intensities, color rendering and color temperatures that allowed users to quickly forget the old incandescent bulbs without sacrificing warm and relaxing light in our living rooms and bedrooms.

Depending on the facility, different kinds of light sources can be used in different parts of one given sport installation. Their most important characteristics in terms of visual performance for different kinds of users of sports facilities and energy consumption, for installation management, are discussed below:

\subsubsection{Metal Halide Lamps}

The metal halide is a discharge lamp, that is, one lamp without a filament where an electrical arch interacts with a filling gas emitting white light. The filling gas incorporates mercury and metal halides to enhance certain parts of the visible spectrum and, hence, improve the emitted light and its color rendering, which is critical for performance in sports facilities.

Metal halide lamps require very high voltage ignition. Hence, they need a starter, a ballast and a capacitor in a series with the tube for operation, which means additional energy consumption.

This type of lamp is used for applications where high illumination levels together with good color rendering is necessary. Hence, they are one of the most used light sources in sports facilities to illuminate both the competition and bleachers.

\subsubsection{High Pressure Sodium (HPS) Lamps}

High pressure sodium lamps are also discharge lamps. They emit light with a lower color temperature (warmer color) and have a lower color rendering, but much higher energy efficiency than metal halide light sources. Visible radiation is produced by the discharge in an atmosphere containing sodium and mercury.

Due to their poor color rendering when compared to metal halide, HPS light sources are scarcely used in sports facilities to illuminate the competition or the bleachers. However, some interesting attempts have been carried out to implement these light sources for sports illumination. The best known is the white sodium technology.

Anyhow, the rare use of HPS lamps to illuminate the sport scene itself is counterbalanced by their frequent use in other important zones of the facility such as the exterior parking or surrounding streets.

Like metal halide lamps, they also need auxiliary electrical devices that increase their energy consumption.

\subsubsection{LED Technology}

The predominance of discharge lamps for the illumination of sports facilities has been decreasing recently due to the quick advances of light-emitting diodes (LED).

LEDs are electronic components (semi-conductors) that, under certain conditions, emit electromagnetic radiation. Although LEDs can emit radiations at all wavelengths (infrared for telecommunications, ultraviolet for medical applications, etc.), their use in lighting is restricted to the visible wavelengths.

The main problem with the use of LEDs in sports facilities has always been the need for high luminous intensities and good color rendering. For this reason, they were not an option in these kinds 
of installations until recent times. However, the development of the first blue LED by Prof. Nakamura (Nobel in Physics 2014) was the starting point [11] which allowed LEDs emitting white light and their subsequent use in sports facilities.

The use of LEDs in sport installations is an important objective for optimal management for several reasons:

- Although their price is high if compared to other light sources, their long life, low consumption and the accurate luminous fluxes recently reached recently make them a real and profitable option now [12];

- LEDs can be dimmed without a negative impact on their lifetime, and thus the luminous flux can be easily increased or decreased depending on the necessities;

- The non-visual effect of the light emitted by LEDs makes them accurate for enhanced performance.

In summary, LED technology can provide different colors or luminous fluxes for different areas or in one given area for different moments. This important fact allows a better performance from all the perspectives of sport facilities and the installations around them such as urban surroundings.

In fact, the unfortunate and frequent cases of violence in the neighborhoods of stadiums make good lighting necessary in these areas in order to enhance not only the actual safety but also the perceived safety, which is a concept gaining more and more importance recently [13].

\subsection{Non-Visual Effects of Light: Performance and Influence on Well-Being}

The effects of light on human physiology and psychology have been well known for ages. For the purposes of this research, the most important effects are those produced on the circadian rhythms (oscillations of our body that last about a day such as the sleep-wake cycle, the cycle of body temperature) and emotions.

Circadian rhythms are mainly mediated by the suprachiasmatic nucleus, a small group of neurons that functions as a regulator of the human organism or internal clock, as it is also known colloquially [14]. On the other hand, emotions are mainly mediated by the limbic system, especially the amygdala [15].

Regarding the light, one of the most important aspects is the circadian rhythm of melatonin or the melatonin cycle. This neurohormone secreted by the pineal gland takes part in important processes such as relaxing, sleep and the decrease of attention and arousal. The higher the level of melatonin, the higher the sleepiness and lower the attention-related processes. On the other hand, its inhibition leads to an increase our levels of alertness and we wake up. In this sense, cortisol, another hormone whose cycle also responds to light levels, plays an antagonistic role to melatonin and its presence helps us maintain alertness levels necessary for everyday life.

High levels of white LED lighting (containing blue wavelengths) promote melatonin inhibition and, hence, intense emotional responses [7], attention and alertness [16], whereas moderate levels with halogen or warm fluorescent lamps promote relaxation.

The new trends in sports lighting are increasingly seeking greater concentration and better performances from athletes as well as lower energy consumption in lighting. Therefore, some arenas and sports centers have their LED lighting as a form of good visual comfort in addition to the advantages described. The main drawbacks of LED lighting are their high price and lower luminous flux, with a consequent need for more units.

In summary, there is still a long way to go in the field relating indissolubly new light sources with the full use of their non-visual effects. If we add to this challenge the recent findings pointing to new and more complex interactions between light and the limbic system, among others, the resulting scenario to take advantage of all the non-visual effects of light is even more complex.

Departing from the considerations above on apparently separate fields such as violence among spectators, lighting technology and the effects of light on humans, this study proposes a dynamic 
lighting installation in sports facilities in order to decrease violence among spectators via the non-visual effects of light.

\section{Materials and Methods}

Although the regulation and recommendations in matter of illumination are well established for the sport activity itself, there is a wide range of variability in other installations belonging to the sport facility (bleachers, changing rooms, surrounding streets ... ) that have a deep impact in sport performance, facility profitability and sustainability even higher than the court itself.

In this work the general recommendations of standards EN 12464-1: 2011 (Lighting of work places. Part 1: Indoor work places) (2011), [17] EN 12464-2: 2007 (Lighting of work places. Part 2: Outdoor work places) (2007) [18], and EN 12193: 2007 (Light and Lighting-Sports Lighting) (2007) [19], will be followed as starting point to achieve the objectives described in the next section. In addition, the recommendations concerning energy requirements for the sake of sustainability settled in EN 15193: 2007 (Energy performance of buildings. Energy requirements for lighting) (2007) [20] are also duly.

\section{Results}

A practical approach to the lighting installation in three zones of the sport facility is proposed. The target is to optimize the installation usage while maximizing arousal in athletes and minimizing stress and potential violent actions among spectators. The decrease of violent actions related to sports spectators has deep implications in terms of finance and security, but also for the sport itself to become a real tool for the integration of different groups at risk of exclusion that use violence as an escape valve and run away from their frustration.

Feasible proposals for the optimization of sports facilities in terms of visual ergonomics vary according to the area they are addressed. The following illumination philosophy is proposed for three specific installations of the sports facility: urban surroundings, changing rooms and heating zones and bleachers. Then, an estimation of the impact on the non-visual path of melatonin is presented. The choice of this non-visual path is due to its close and well-established relationship with some behavior-related effects such as arousal, stress or concentration.

\subsection{Urban Surroundings of the Sports Facility and Access Area}

The high number of violent actions that take place before or after the competition in the surroundings of stadiums and other sports facilities [21,22] make these zones extremely important when considering the global impact of sports in general and competitions in particular on the well-being of people, the management of sports facilities and the use of sports as a tool for the integration of some groups at risk of exclusion.

For this reason, this work will consider adjacent streets and neighborhoods as a part of the facility itself. The present research proposes that any attempt to optimize the management of sports facilities from all perspectives (energy consumption, maintenance, insurance, prevention of violent actions and use of sport as a tool for integration) must consider actions on the urban surroundings as proposed in this work. This need is even more acute when dealing with illumination, given its impact on these aspects.

More concretely, the present proposal supports adjacent urban installations providing white light in order to facilitate facial recognition to dissuade people from violent acts. The illuminance levels should be considered as one category higher than those recommended by the standards in the hour preceding and following competitions. Hence, the regulation of lighting levels together with the need for white light make LEDs the best option for these zones. The potential advantage of white light to decrease insecurity is due to its better chromatic reproduction which helps in facial recognition $[13,23]$. 


\subsection{Changing Rooms and Heating Zones: A Mix Illumination Is Proposed Depending on the Use}

The illumination of these zones of the sports facility where the athletes get ready for a competition or where they have a rest after the match is also a critical issue due to its influence on sports performance and later recovery.

There have been brilliant attempts to optimize the sports performance in the court by means of an accurate lighting installation [24]. However, in this work it is considered that a smart use of light must start before competition or training. Thus, the changing rooms and heating zones are a target of such optimization. More specifically, the following actions are proposed:

- Training and hours before the competition: cold illumination $(\mathrm{Tc}=6500 \mathrm{~K})$ and high levels of illuminance (750 lux on the working plane) are proposed. These values instill an enhancement in alertness and arousal without exceeding the limits established by the regulations.

Regarding this proposal, although UNE-EN 12464:2012 recommends a minimum illuminance of $\mathrm{E}=300$ lux, this regulation refers designers to UNE-EN 12193:2009 which is specific for sports facilities. This last standard establishes a maximum color temperature (or correlated color temperature when using discharge lamps) of $\mathrm{Tc}=6500 \mathrm{~K}$. This value is rarely reached because changing rooms and heating zones usually use standard fluorescent tubes with $\mathrm{Tc}=4000-4500 \mathrm{~K}$. Hence, this proposal goes to the limit of the regulation without breaking it.

According to preceding investigations, the combination of these moderate to high levels and the rather cold color temperature will act via the intrinsically photosensitive Retinal Ganglion Cells (ipRGC) cells with the consequent inhibition of melatonin from the pineal gland and cortisol release from the suprarenal glands. Exposure to these installations of longer than $30 \mathrm{~min}[16,25]$ can be considered enough to launch these processes.

The improved excitation allows shorter reaction times [26-28], which are extremely important in most sports, especially those involving speed or the use of fast balls (tennis, table tennis, hockey, martial arts, etc.).

- Rest and hours after competition: a warm illumination $(\mathrm{Tc}=3000 \mathrm{~K})$ and moderate-low levels of illuminance (300 lux on the working plane) are proposed. These values should facilitate relaxation and melatonin secretion without exceeding the limits established by the regulations. Anyhow, this illumination is not suitable for short breaks as it could make athletes lose their arousal and concentration.

The possibility to provide dual lighting with such a wide range of illumination levels and color temperatures makes it necessary to use adjustable LED installations capable of being dimmed and including trichromatic LED arrays that can play with the three primary colors and achieve the necessary color temperature in each case.

\subsection{Bleachers}

As mentioned above, one important problem in sports events is violence among spectators. Hence, any attempt to avoid excessive stress among spectators is necessary. In addition, besides the obvious direct consequences of violence, its decrease means a remarkable profit from the point of view of security and maintenance, as well as the opportunity for sports to become a tool for the integration of groups at risk of exclusion due to trends of violence.

The following sequence of lighting is proposed:

- From the opening of the stadium until the beginning of the competition: warm lighting ( $\mathrm{Tc}=3000 \mathrm{~K})$ with low levels of illumination (20 lux) is proposed. This way, the level of stress of the spectators is decreased. 
- During competition: a neutral to moderately cold color temperature ( $\mathrm{Tc}=4500-5000 \mathrm{~K}$ ) with low levels of illumination (depending on the kind of competition) is proposed. This way, the spectators can get involved and better enjoy the game.

- After competition: warm lighting ( $\mathrm{Tc}=3000 \mathrm{~K}$ ) with low levels of illumination (20 lux) is proposed to again decrease the stress of spectators generated by the competition and to avoid the frequent violent acts in the surroundings of the stadiums [29-32].

The proposal for the zones under consideration can be summarized in Table 1:

Table 1. Summarized proposal for the zones under consideration.

\begin{tabular}{|c|c|c|c|}
\hline Zone & Lighting Technology & Color Temperature & Illuminance Levels \\
\hline $\begin{array}{l}\text { Urban surroundings } \\
\text { of sport facility }\end{array}$ & LED & 4000 to $5000 \mathrm{~K}$ & $\begin{array}{l}\text { One category higher than } \\
\text { standard before and after the } \\
\text { match. Same as standard when } \\
\text { there is no event. }\end{array}$ \\
\hline $\begin{array}{l}\text { Changing and } \\
\text { heating rooms }\end{array}$ & LED & $\begin{array}{ll}- & 6500 \mathrm{~K} \text { before competition } \\
\text { - } & 3000 \mathrm{~K} \text { after competition }\end{array}$ & $\begin{array}{l}\text { - } \quad 750 \text { lux before competition } \\
\text { - } \quad 300 \text { lux after competition }\end{array}$ \\
\hline Bleachers & LED & $\begin{array}{ll}\text { - } & 3000 \mathrm{~K} \text { before competition } \\
\text { - } & 4500 \text { to } 5000 \mathrm{~K} \\
& \text { during competition } \\
\text { - } & 3000 \mathrm{~K} \text { after competition }\end{array}$ & $\begin{array}{l}\text { - } 20 \text { lux before competition } \\
\text { - Depending on the kind of } \\
\text { competition during } \\
\text { the game } \\
\text { - } 20 \text { lux before competition }\end{array}$ \\
\hline
\end{tabular}

\subsection{Impact on the Non-Visual Path of Melatonin}

Typical radiant spectra of the proposed lighting modes (one with cold and another one with warmer light) have been computed with the Irradiance Toolbolx [33]. Departing from the output, the impact on the melatonin path of each proposal has been estimated. This estimation consists of the evaluation of the "melanopic illuminances", which are shown in Table 2 together with the photopic (visual) illuminances:

Table 2. Impact on the non-visual path of melatonin of two typical commercial LEDs (cold and warmer color temperatures). The photopic and melanopic illuminances (P.I. and M.I.) are displayed.

\begin{tabular}{ccccccc}
\hline & \multicolumn{2}{c}{ Urban Surroundings } & \multicolumn{2}{c}{ Changing Heating Rooms } & \multicolumn{2}{c}{ Bleachers } \\
\hline $\begin{array}{c}\text { Color } \\
\text { Temperature }\end{array}$ & $\begin{array}{c}\text { P.I. } \\
\text { (phot. lux) }\end{array}$ & $\begin{array}{c}\text { M.I. } \\
\text { (melanop. lux) }\end{array}$ & $\begin{array}{c}\text { P.I. } \\
\text { (phot. lux) }\end{array}$ & $\begin{array}{c}\text { M.I. } \\
\text { (melanop. lux) }\end{array}$ & $\begin{array}{c}\text { P.I. } \\
\text { (photop. lux) }\end{array}$ & $\begin{array}{c}\text { M.I. } \\
\text { (melanop. lux) }\end{array}$ \\
\hline Warmer & N.A. & N.A. & 300 (after) & 22.13 (after) & 20 & 1.48 \\
\hline Colder & 20 & 14.21 & 750 (before) & 532.87 (before) & 20 & 14.21 \\
\hline
\end{tabular}

As seen in the Introduction, higher levels of colder light (in general, white light) inhibit melatonin secretion. It is quantified with the melanopic illuminance: the higher the melanopic illuminance, the higher the melatonin suppression, and, hence, concentration and arousal are increased.

Departing from the figures in Table 2, the following remarks can be made:

(1) Changing rooms: A moderate change in photopic illuminance (300 to 750 lux) when going from a warmer to a colder color temperature multiplies the melanopic illuminance by 24 . It means that just a slight increase or decrease in the illumination levels simultaneous to a change in the light color can have a very remarkable impact on the non-visual path of melatonin and, thus, in the way the arousal of athletes is managed before and after competition.

(2) Bleachers: The use of warmer lighting before the competition, when many violent actions take place, ensures a very low melatonin inhibition, which contributes to keeping calm and avoiding 
stress. Then, during competition, the dynamic change of the lighting installation to the emission of colder light fosters participation without reaching strong melatonin inhibition which might cause stress and aggressiveness.

The use of white light in the urban surroundings does not cause effects on the melatonin non-visual path, but instead causes better facial recognition and color rendering, improving people's feelings of safety before and after the match.

\section{Discussion}

Several considerations can be made from the items above:

(1) The management of sports facilities must be considered from a global perspective; that is, besides energy efficiency and financial profitability, the actions to be taken must include sports performance in competition and training, the well-being of athletes and spectators and, last but not least, a real intention to decrease violence inside and outside the facility, which may have a major impact on environmental, cultural, economic and social sustainability;

(2) The decrease of violence among spectators, which is an important problem in many countries and, especially in many sports such as soccer, may help sports to increase their impact on social sustainability through the integration of groups at risk of exclusion. To date, this option has been considered from the perspective of inclusion through playing sports, but this proposal includes speculation itself as a vehicle to avoid violence;

(3) Given the well-known effects of light on human health and psychology, the achievement of an accurate lighting installation will be of the utmost importance when considering sports facilities from this global perspective;

(4) Urban surroundings of the sports facility should be considered as a part of the facility itself when dealing with the lighting installations. In fact, the high number of violent acts in these areas before and after sport events strongly requests this new perspective which is not reported in the literature to date. A dynamic LED illumination is a good method to avoid violence without a huge amount of energy consumption;

(5) Actions on the illumination of changing rooms and heating zones must be prioritized to enhance performance in athletes via the well-known non-visual effects of light on stress and arousal. This influence is due to melatonin inhibition and cortisol secretion. On the other hand, such actions must also include accurate lighting to allow a good recovery after the competition. In summary, both extremes (before and after competition) can be achieved with dimmable LED lighting with a luminous flux and color temperature. It has been demonstrated in this work that the proposed changes in color, depending on the circumstances, may have a remarkable impact on the non-visual path of melatonin;

(6) The bleachers are the zone where many violent acts take place. Thus, illumination levels and color temperature can influence the level of stress and emotional responses in spectators. This leads to the proposal of warmer color temperatures and low to moderate illumination levels from the lighting installation. In this work, the effects of the different possibilities are quantified from the perspective of non-visual effects;

(7) The use of dynamic lighting allowing illumination with different spectra and color temperatures according to the needs of each circumstance allows the installation managers to play with the malanopic illuminance. This illuminance determines the melatonin inhibition rate and, hence, has a remarkable influence on the levels of stress and arousal or, on the other hand, the possibility of relaxation of the facility users.

Acknowledgments: This research was partially implemented with financial support provided by CAPES, Higher Education Personnel Improvement Coordination-Brazil, through the Doctoral scholarship (BEX 0947/14-8). 
Author Contributions: All the authors have equally contributed to this article.

Conflicts of Interest: The authors declare no conflict of interest. The founding sponsors had no role in the design of the study; in the collection, analyses, or interpretation of data; in the writing of the manuscript, and in the decision to publish the results.

\section{References}

1. Tenenbaum, G.; Stewart, E.; Singer, R.N.; Duda, J. Aggression and violence in sport: An ISSP position stand. J. Sports Med. Phys. Fit. 1997, 37, 146-150. [CrossRef]

2. Fitzpatrick, B. Broken Bats and Broken Bones: Holding Stadium Owners Accountable for Alcohol-Fueled Fan-on-Fan Violence. Jeffrey S. Moorad Sports LJ 2015, 22, 663.

3. Warren, I. Violence in sport: Some theoretical and practical issues in the Australian context. In Proceedings of the Second National Conference on Violence, Australian Institute of Criminology, Canberra, Australia, 15-18 June 1993.

4. Terry, P.C.; Jackson, J.J. The determinants and control of violence in sport. Quest 1985, 37, 27-37. [CrossRef]

5. Donahue, E.G.; Rip, B.; Vallerand, R.J. When winning is everything: On passion, identity, and aggression in sport. Psychol. Sport Exerc. 2009, 10, 526-534. [CrossRef]

6. Martin, J.M.; Juvina, I.; Lebiere, C.; Gonzalez, C. The effects of individual and context on aggression in repeated social interaction. Appl. Ergon. 2013, 44, 710-718. [CrossRef] [PubMed]

7. Vandewalle, G.; Schwartz, S.; Grandjean, D.; Wuillaume, C.; Balteau, E.; Degueldre, C.; Schabus, M.; Phillips, C.; Luxen, A.; Dijk, D.J.; et al. Spectral quality of light modulates emotional brain responses in humans. Proc. Natl. Acad. Sci. USA 2010, 107, 19549-19554. [CrossRef] [PubMed]

8. Sander, D.; Grandjean, D.; Pourtois, G.; Schwartz, S.; Seghier, M.L.; Scherer, K.R.; Vuilleumier, P. Emotion and attention interactions in social cognition: Brain regions involved in processing anger prosody. Neuroimage 2005, 28, 848-858. [CrossRef] [PubMed]

9. Van Bommel, W.J. Non-visual biological effect of lighting and the practical meaning for lighting for work. Appl. Ergon. 2006, 37, 461-466. [CrossRef] [PubMed]

10. Parsons, K.C. Ergonomics of the physical environment: international ergonomics standards concerning speech communication, danger signals, lighting, vibration and surface temperatures. Appl. Ergon. 1995, 26, 281-292. [CrossRef]

11. Nakamura, S. Development of the Blue Light-Emitting Diode; SPIE Newsroom: Washington, DC, USA, 2015.

12. Valentim, A.A.; Ferreira, H.S.; Coletto, M.A. LED Lamps: Impact and Factor on power consumption. Ciênc. Ambient. Mag. On-Line 2010, 6, 29-33.

13. Peña-García, A.; Hurtado, A.; Aguilar-Luzón, M.C. Impact of public lighting on pedestrians' perception of safety and well-being. Saf. Sci. 2015, 78, 142-148. [CrossRef]

14. Saper, C.B.; Scammell, T.E.; Lu, J. Hypothalamic regulation of sleep and circadian rhythms. Nature 2005, 437, 1257-1263. [CrossRef] [PubMed]

15. Catani, M.; Dell'acqua, F.; de Schotten, T.M. A revised limbic system model for memory, emotion and behaviour. Neurosci. Biobehav. Rev. 2013, 37, 1724-1737. [CrossRef] [PubMed]

16. Chellappa, S.L.; Steiner, R.; Blattner, P.; Oelhafen, P.; Götz, T.; Cajochen, C. Non-visual effects of light on melatonin, alertness and cognitive performance: Can blue-enriched light keep us alert? PLoS ONE 2011, 6, e16429. [CrossRef] [PubMed]

17. European Committee for Standardization (CEN). Lighting of Work Places. Part 1: Indoor Work Places; European Standard EN 12464-1: 2011; CEN: Brussels, Belgium, 2011.

18. European Committee for Standardization (CEN). Lighting of Work Places. Part 2: Outdoor Work Places; European Standard EN 12464-2: 2007; CEN: Brussels, Belgium, 2007.

19. European Committee for Standardization (CEN). Light and Lighting—Sports Lighting; European Standard EN 12193: 2007; CEN: Brussels, Belgium, 2007.

20. European Committee for Standardization (CEN). Energy Performance of Buildings. Energy Requirements for Lighting; European Standard EN 15193: 2007; CEN: Brussels, Belgium, 2007.

21. Kurland, J.; Johnson, S.D.; Tilley, N. Offenses around stadiums: A natural experiment on crime attraction and generation. J. Res. Crime Delinq. 2013. [CrossRef] 
22. Schwambach, K.F. Mega events in Rio de Janeiro and their influence on the city planning. In Proceedings of the 15th International Planning History Society Conference, São Paulo, Brazil, 15-18 July 2012.

23. Raynham, P.; Saksvikrønning, T. White Light and Facial Recognition. Light. J. 2003, 68, $29-33$.

24. Lemons, T.M.; Rosen, S.; Gernetzke, C.; Lussier, B. Light Emitting Diode (LED) Sports Lighting Luminaire Assembly. U.S. Patent 8,998,449, 7 April 2015.

25. Brainard, G.C.; Hanifin, J.P.; Greeson, J.M.; Byrne, B.; Glickman, G.; Gerner, E.; Rollag, M.D. Action spectrum for melatonin regulation in humans: Evidence for a novel circadian photoreceptor. J. Neurosci. 2001, 21, 6405-6412. [PubMed]

26. Fletcher, D.; Hanton, S.; Mellalieu, S.D.; Neil, R. A conceptual framework of organizational stressors in sport performers. Scand. J. Med. Sci. Sports 2012, 22, 545-557. [CrossRef] [PubMed]

27. Mori, S.; Ohtani, Y.; Imanaka, K. Reaction times and anticipatory skills of karate athletes. Hum. Mov. Sci. 2002, 21, 213-230. [CrossRef]

28. Singer, R.N.; Cauraugh, J.H.; Chen, D.; Steinberg, G.M.; Frehlich, S.G. Visual search, anticipation, and reactive comparisons between highly-skilled and beginning tennis players. J. Appl. Sport Psychol. 1996, 8, 9-26. [CrossRef]

29. Collins, M. Sport, physical activity and social exclusion. J. Sports Sci. 2004, 22, 727-740. [CrossRef] [PubMed]

30. Raspaud, M.; da Cunha Bastos, F. Torcedores de futebol: Violence and public policies in Brazil before the 2014 FIFA World Cup. Sport Soc. 2013, 16, 192-204. [CrossRef]

31. Skinner, J.; Zakus, D.H.; Cowell, J. Development through sport: Building social capital in disadvantaged communities. Sport Manag. Rev. 2008, 11, 253-275. [CrossRef]

32. Zani, B.; Kirchler, E. When violence overshadows the spirit of sporting competition: Italian football fans and their clubs. J. Community Appl. Soc. Psychol. 1991, 1, 5-21. [CrossRef]

33. Lucas, R.J.; Peirson, S.N.; Berson, D.; Brown, T.; Cooper, H.; Czeisler, C.A.; Figueiro, M.G.; Gamlin, P.D.; Lockley, S.W.; O'Hagan, J.B.; et al. Irradiance Toolbox. 2013. Available online: https://www. google.com / url?sa=t\&rct=j\&q=\&esrc=s\&source=web\&cd=1\&ved=0ahUKEwjanuHPiubQAhVGoJQKH fbeAMgQFggcMAA\&url=https $\% 3 \mathrm{~A} \% 2 \mathrm{~F} \% 2 \mathrm{Fwww}$.ndcn.ox.ac.uk $\% 2$ Fteam $\% 2$ Fstuart-peirson $\% 2 \mathrm{Fdownl}$ oadstile-14\%2Ffiletile-4\%2F\%40\%40download\&usg=AFQjCNEN1Tekueez_DTLiArKLoN2nvySYA\&sig2= _5qcYwpC0P8887NcPZ-1sg\&cad=rja (accessed on 25 September 2016).

(C) 2016 by the authors; licensee MDPI, Basel, Switzerland. This article is an open access article distributed under the terms and conditions of the Creative Commons Attribution (CC-BY) license (http://creativecommons.org/licenses/by/4.0/). 